\title{
Internal Fetal Rotation
}

National Cancer Institute

\section{Source}

National Cancer Institute. Internal Fetal Rotation. NCI Thesaurus. Code C92817.

A finding during labor, in which the occiput rotates anteriorly and the head of the fetus assumes an oblique orientation while the fetus descends through the maternal pelvis. 